\title{
The Influence of Palm Oil Addition on Sunflower Halva Stability and Texture
}

\author{
Vlad MUREŞAN ${ }^{* 1}$, Sabine DANTHINE ${ }^{2}$, Emil RACOLŢA ${ }^{1}$, Sevastiţa MUSTE ${ }^{1}$, Christophe BLECKER ${ }^{2}$, An- \\ drei BORŞA ${ }^{1}$, Elena Andruţa MUREŞAN ${ }^{1}$ \\ ${ }^{1}$ Food Engineering Department, Faculty of Food Science and Technology, University of Agricultural Sciences and \\ Veterinary Medicine Cluj-Napoca - R0-400509 - Cluj-Napoca, Calea Floreşti, 64, Romania, \\ ${ }^{2}$ Food Science and Formulation Department, Gembloux Agro-Bio Tech, University of Liege - B-5030 - Gembloux, \\ Passage des Déportés, 2, Belgium, \\ *vlad.muresan@usamvcluj.ro
}

Bulletin UASVM Food Science and Technology 71(1) / 2014

ISSN-L 2344-2344; Print ISSN 2344-2344; Electronic ISSN 2344-5300

\begin{abstract}
Halva is one of the most popular food products of Middle Eastern and North African countries. Worldwide, the most known halva contains roasted sesame seeds, while usually in Eastern European countries the most appreciated is sunflower halva. However, even if sunflower halva is an appreciated product, it has currently a quality below the expectations of the new generation of consumers. Sunflower halva main issue is caused by the oil which separates at the surface during storage, determining a low commercial aspect of the product. Thus, the aim of this work was to assess the influence of palm oil addition on sunflower halva stability and texture. Five samples containing different oil percentages $[\mathrm{w} / \mathrm{w}](1 \%, 2 \%, 3 \%, 4 \%, 5 \%)$ were prepared, as well as a control sample prepared using the standard recipe (no palm oil added). The texture of all samples was analyzed by an instrumental method, while the colloidal stability was determined by a gravimetric technique during 40 days of storage at two different temperatures $\left(1-2^{\circ} \mathrm{C}\right.$ and $\left.15-20^{\circ} \mathrm{C}\right)$. After the storage test at $1-2 \mathrm{oC}$, there were not significant differences between the samples, for all palm oil containing samples as well as for control, the percentages of separated oil being below $0.6 \%$. With respect to the control sample, the halva samples containing $1 \%$, $4 \%$ and $5 \%$ of palm oil showed a decrease in their stability, while samples containing $2 \%$ and $3 \%$ showed an improved stability (3.44\% and $1.78 \%$ of separated oil). During this study it was established that the sample containing $3 \%$ palm oil was the most favorable, regarding its textural properties, as well as its colloidal stability.
\end{abstract}

Keywords: oil separation problem, halva stability, halva texture, palm oil, tahini.

\section{INTRODUCTION}

Halva specific texture derives from a mixture of nougat - sugar and glucose syrup beat with soapwort (Saponaria officinalis) extract and tahini - a paste produced by milling roasting seeds or nuts (Eissa and Zohair, 2006). In Eastern European countries halva recipe has been adapted since years by using as main raw material sunflower seeds due to their high availability in this region (Mureşan et al., 2010). Sunflower (Helianthus annuus) originates from Central and North America being one of the most important oil crops. Products using sunflower seeds as their raw material are characterized by a balanced nutritional composition (Gulya, 2004). Among oil crops worldwide, sunflower seed ranks seventh behind soybean, palm, coconut, rapeseed, cottonseed and peanuts (FAO, 2013). Most of the sunflower seed crop is crushed for oil, while just a tiny proportion of the global sunflower crop is directly eaten as "nuts" or kernels, or processed as sunflower butter or sunflower halva (Mureşan, 2012). As sunflower seed oil market is affected by 
competition with less expensive vegetal oils (e.g., soybean, palm, etc.), one way to maintain and expand the sunflower seed market by increasing its demand as raw material, is to improve the quality of value-added sunflower products, including halva.

Fatty acid profile of regular sunflower tahini oil is made up of $11 \%$ saturated fatty acids, $20 \%$ oleic acid and 69\% linoleic acid (Fernández-Martínez et al., 2009). As there are high concentrations of unsaturated lipids of sunflower tahini, the fat phase is in a liquid form, being prone to exudate. The oil separation problem of sesame and sunflower halva and tahini, as well as the stability of nut spreads is a current problem, recently published papers discussing this issue (Guneser and Zorba, 2011; Mureşan et al., 2013; Shakerardekani et al., 2013; Elleuch et al., 2014).

Naturally sunflower tahini fat is mainly unsaturated, being in liquid form at ambient temperature (between 0 and $35^{\circ} \mathrm{C}$, the solid fat content is $0 \%$ ), thus tahini dispersion, if allowed to stand at room temperature conditions for extended period tends to break down in two layers: sunflower oil rising to the surface, and a dry compact layer of sunflower solids deposited at the bottom of the package, similar to other food dispersions (Fig. 1). As more than half of the halva consists of tahini, the halva stability is also affected, the product having an oily surface and packaging which determines a very low commercial aspect.
Due to these issues, the sunflower halva is totally uncompetitive with other products from its range, especially chocolate, a modern product with a superior quality.

Consequently, even if sunflower halva is an appreciated product, it has currently a quality below the expectations of the new generation of consumers, the product quality improvement being a need. From available literature data (Lidefelt, 2007), it was considered that addition of a saturated fat will allow the development of a network structure which immobilizes the free oil (Fig. 1), preventing its migration. Palm oil was identified as a vegetable oil which has a considerable solid fat content $\left(30 \%\right.$ at $20^{\circ} \mathrm{C}$ and $50 \%$ at $10^{\circ} \mathrm{C}$ ). Thus, the aim of this work was to assess the influence of palm oil addition on sunflower halva stability and texture.

\section{MATERIALS AND METHODS}

The nougat and sunflower tahini were obtained by traditional technology (Fig. 2). In order to efficiently obtain different prototypes, the kneading as well as molding was performed at Laboratory scale $(\sim 20 \mathrm{~g} / \mathrm{bar})$.

In order to assess the influence of palm oil addition, samples containing different palm oil percentages $[\mathrm{w} / \mathrm{w}](1 \%, 2 \%, 3 \%, 4 \%, 5 \%)$ were prepared (Tab. 1). A control sample was prepared using the standard recipe (no palm oil added).

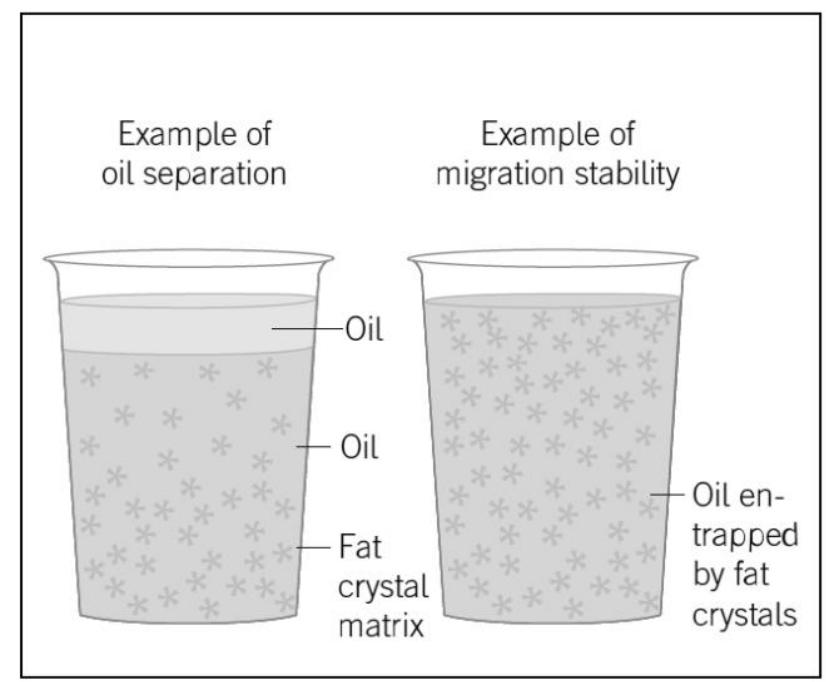

Fig. 1. Schematic view of destabilization phenomena on food suspensions with oil continuous phase (Source: Lidefelt, 2007) 
For texture analysis a Brookfield CT3 Texture Analyzer equipped with the Knife Edge (Clear Acrylic 8g. $60 \mathrm{~mm}$ Wide) was used, Test speed being set at $0.5 \mathrm{~mm} / \mathrm{s}$, Pre-test speed at $0.5 \mathrm{~mm} / \mathrm{s}$, Posttest speed at $4.5 \mathrm{~mm} / \mathrm{s}$. Results were processed by using the Texture Pro CT software.

All samples were stored for 40 days at two different temperatures $\left(1-2^{\circ} \mathrm{C}\right.$ and $\left.15-20^{\circ} \mathrm{C}\right)$. During storage the colloidal stability of all samples was evaluated by a gravimetric technique, with a precise determination of the percentages of the exudate oil. The sample was wrapped in perforated aluminum foil, and then placed on three rods (for spacing the sample from absorbent paper) with the perforated side down, into a suitable container padded with absorbent paper in advance. Exudate oil leaked through perforations and was absorbed by the paper, being quantified gravimetrically. The

Table 1. Sunflower halva prototypes and control sample ingredients ratios - Experimental design

\begin{tabular}{|c|c|c|c|c|c|}
\hline & Palm oil & \multicolumn{2}{|c|}{$\begin{array}{c}\text { Tahini } \\
\text { [\%] }\end{array}$} & Nougat & Halva \\
\hline & & \multicolumn{2}{|c|}{60.00} & & \\
\hline \multirow[t]{3}{*}{ Control } & 0 & Fat & Non-fat & 40.00 & 100.00 \\
\hline & & 36.00 & 24 & & \\
\hline & & \multicolumn{2}{|c|}{59.00} & & \\
\hline \multirow[t]{3}{*}{ H_palm 1\% } & 1.00 & Fat & Non-fat & 40.00 & 100.00 \\
\hline & & 35.40 & 23.60 & & \\
\hline & & \multicolumn{2}{|c|}{58.00} & & \\
\hline \multirow[t]{3}{*}{ H_palm $2 \%$} & 2.00 & Fat & Non-fat & 40.00 & 100.00 \\
\hline & & 34.80 & 23.20 & & \\
\hline & & \multicolumn{2}{|c|}{57.00} & & \\
\hline \multirow[t]{3}{*}{ H_palm3\% } & 3.00 & Fat & Non-fat & 40.00 & 100.00 \\
\hline & & 34.20 & 22.80 & & \\
\hline & & \multicolumn{2}{|c|}{56.00} & & \\
\hline \multirow[t]{3}{*}{ H_palm4\% } & 4.00 & Fat & Non-fat & 40.00 & 100.00 \\
\hline & & 33.60 & 22.40 & & \\
\hline & & \multicolumn{2}{|c|}{55.00} & & \\
\hline \multirow[t]{2}{*}{ H_palm5\% } & 5.00 & Fat & Non-fat & 40.00 & 100.00 \\
\hline & & 33.00 & 22.00 & & \\
\hline
\end{tabular}




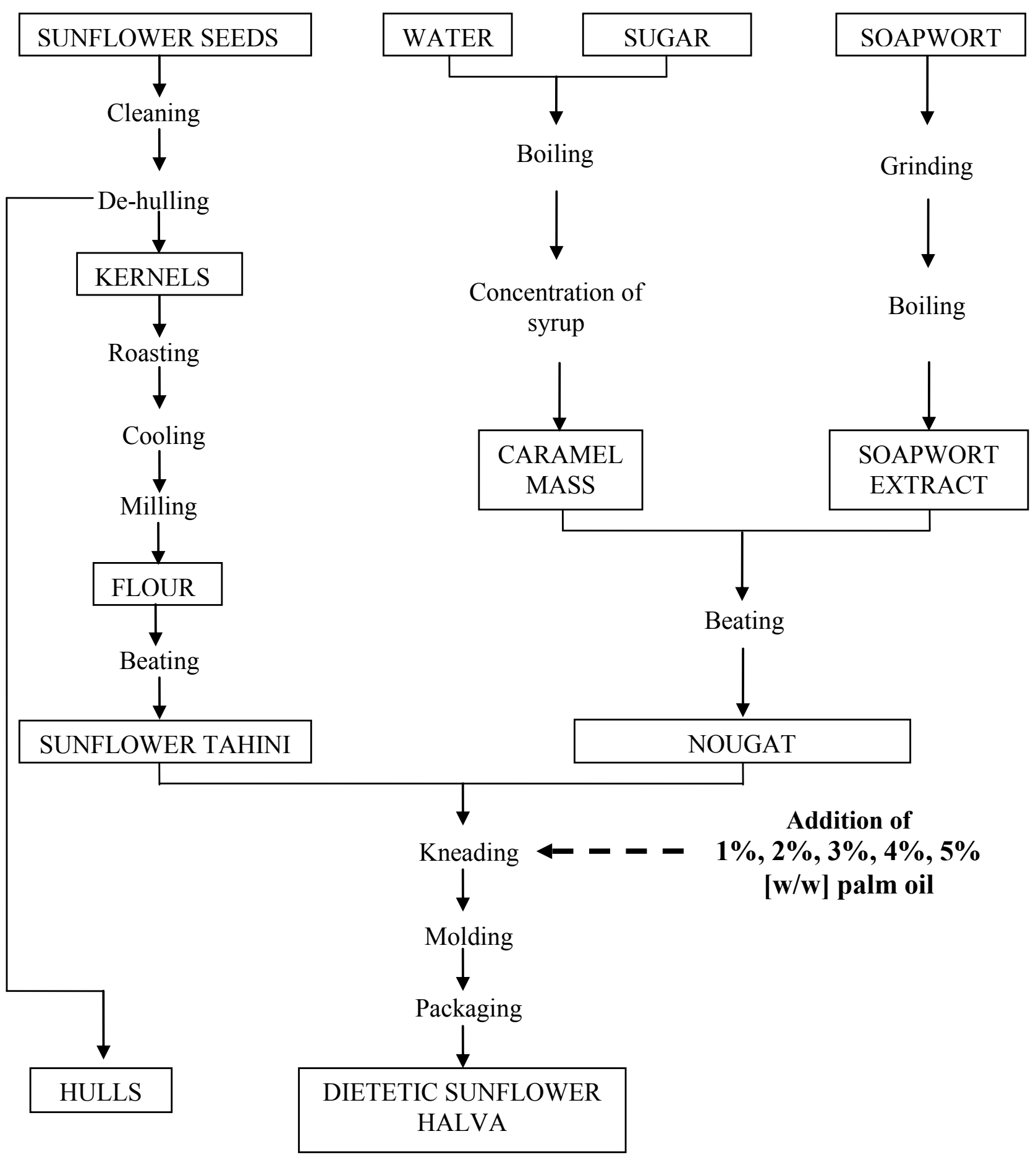

Fig. 2. Technological flow used for the manufacturing of sunflower halva prototypes with added palm oil 
result was expressed in \% by mass, of separated oil from the sample.

\section{RESULTS AND DISCUSSIONS}

After the storage test at $1-2^{\circ} \mathrm{C}$, there were not significant differences between the samples, the percentages of separated oil being below $0.6 \%$ (Fig. 3), for all palm oil containing samples as well as for control. The results might be explained by the relatively high viscosity of the continuous oil phase caused by the low storage temperatures (1$2^{\circ} \mathrm{C}$ ), determining a very slow exudation of the oil from the products.
On the other hand, for higher storage temperature conditions (Fig. 4), after 40 days of storage at $15-20^{\circ} \mathrm{C}$ the control sample had separated $4.53 \%$, very close to the sample containing $1 \%$ and $5 \%$ palm oil ( $4.91 \%$ and $4.77 \%)$. With respect to the control sample, the halva samples containing $1 \%$, $4 \%$ and $5 \%$ of palm oil showed a decrease in their stability, while samples H_palm $2 \%$ and H_palm $3 \%$ showed an improved stability $(3.44 \%$ and $1.78 \%$ of separated oil).

Regarding the texture measurements the analysis revealed very close textures for control and samples containing 1 and $2 \%$ palm oil (load

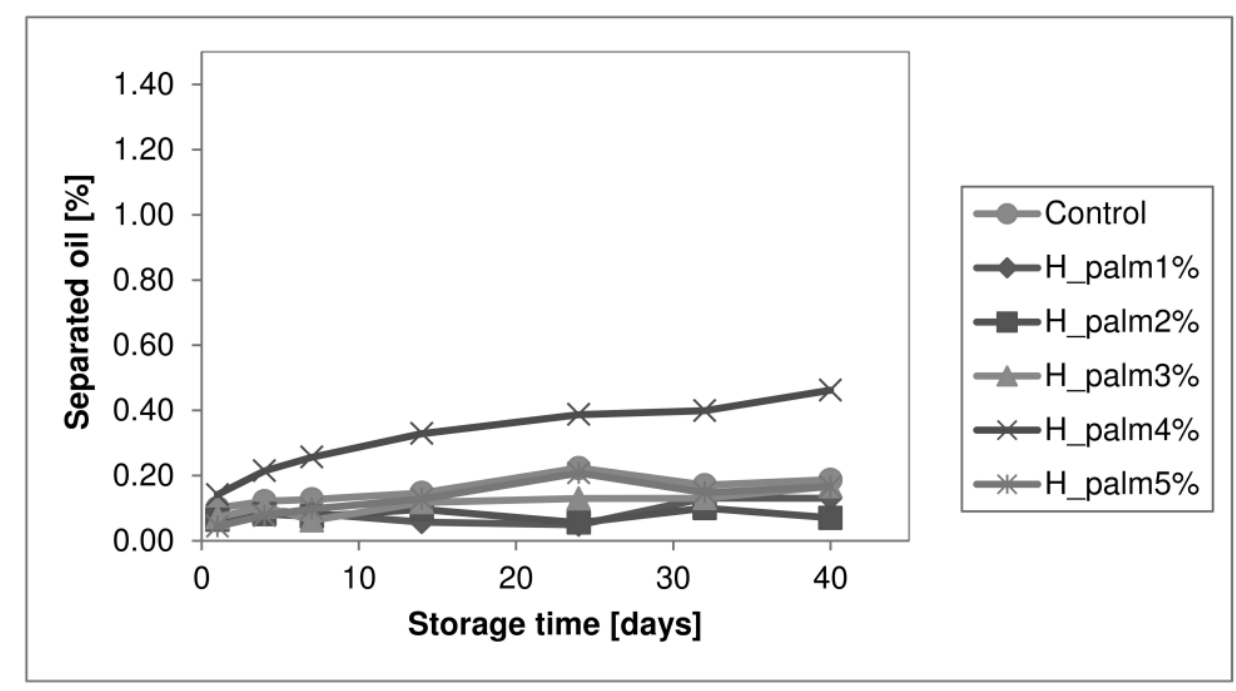

Fig. 3. The colloidal stability of sunflower halva palm oil prototypes and control sample stored 40 days at $1-2^{\circ} \mathrm{C}$

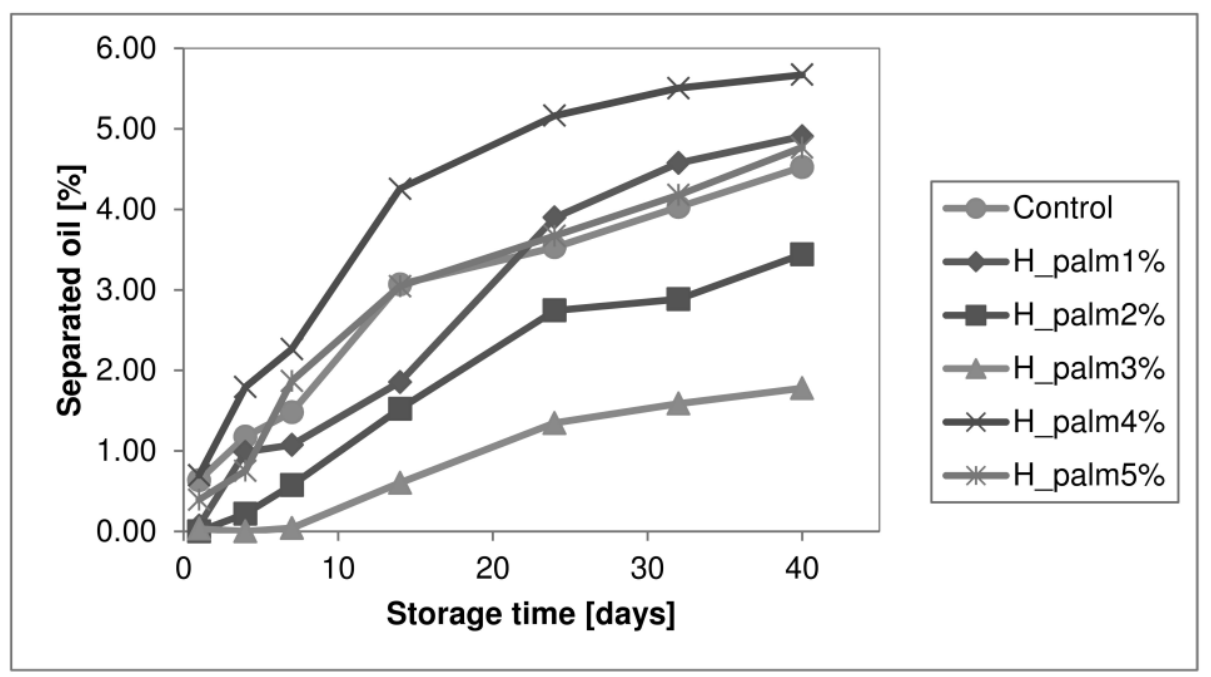

Fig. 4. The colloidal stability of sunflower halva palm oil prototypes and control sample stored 40 days at $15-20^{\circ} \mathrm{C}$ 


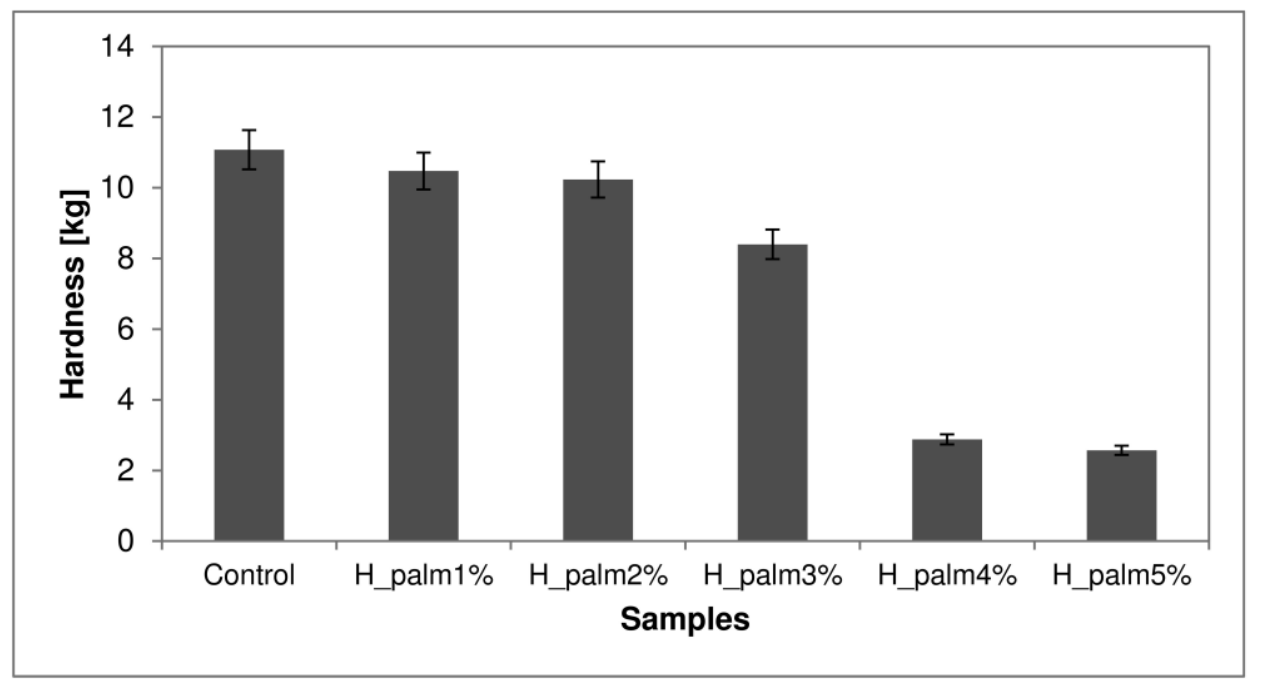

Fig. 5. Hardness of sunflower halva palm oil prototypes and control sample

of around $10 \mathrm{~kg}$ ), while samples containing $4 \%$ and $5 \%$ showed a very soft texture (load of $2 \mathrm{~kg}$ ). These two samples, due to the high proportion of the palm oil were unmolded with difficulties. It worth to be mentioned that sample containing $3 \%$ of palm oil showed an improved texture with an intermediate hardness of $8 \mathrm{~kg}$ (Fig. 5).

\section{CONCLUSION}

At $1-2^{\circ} \mathrm{C}$ no practical significant differences were recorded, the separated oil being for all samples less than $0.6 \%$, while at $15-20^{\circ} \mathrm{C}$ the halva sample with $3 \%$ palm oil had the lowest oil separated. For more than 3\% palm oil addition, there is a supplementary fat addition with negative impact on halva stability and texture.

During this study it was established that the sample containing 3\% palm oil was the optimum, regarding its textural properties, as well as its colloidal stability.

\section{REFERENCES}

1. Eissa, A. H. and Zohair, A. (2006). Quality and safety of halawa modified with mushroom, J. Sci. Food Agric., 86:2551-2559.

2. Elleuch, M. et al. (2014). Improving halva quality with dietary fibres of sesame seed coats and date pulp, enriched with emulsifier. Food Chemistry, 145: 765-771.
3. FAO (2013). Statistics, Food and Agriculture Organization of the United Nations (http://faostat3.fao.org/)

4. Fernández-Martínez, J.M. et al. (2009). Sunflower. In: D. J. Vollmann and I. Rajcan (Eds.). Handbook of plant breeding - Oil crops. Springer Science, New York, US.

5. Gulya, T.J. (2004). Sunflower. In: C. Wrigley (Ed.). Encyclopedia of Grain Science. Elsevier Ltd.

6. Guneser, O. and Zorba, M. (2011). Effect of emulsifiers on oil separation problem and quality characteristics of Tahin Helva during storage, J Food Sci Technol, DOI 10.1007/s13197-011-0594-7.

7. Lidefelt, J.O. (2007). Chocolate and confectionery, p. 112146. In: J.O. Lidefelt (ed.). Handbook of Vegetable Oils and Fats. AAK AB, Karlshamn, Sweden.

8. Mureşan, V. et al. (2010). Determination of Peroxide Value in Sunflower Halva using a Spectrophotometric Method, Bulletin UASVM Agriculture, 67(2): 334-339.

9. Mureșan, V. (2012). Researches regarding colloidal and oxidative stability of confectionery products (halva) obtained from sunflower. PhD Thesis, USAMV Cluj-Napoca Faculty of Agriculture, University of Liege - Gembloux AgroBio Tech.

10. Mureșan, V. et al. (2013). Confectionery products (halva type) obtained from sunflower: production technology and quality alterations - a review. Biotechnology, Agronomy, Society and Environment, 17: 651-659.

11. Shakerardekani, A. et al. (2013). Textural, Rheological and Sensory Properties and Oxidative Stability of Nut Spreads - A Review, Int. J. Mol. Sci., 14: 4223-4241. 